\title{
Risk factors for an acute exacerbation of idiopathic pulmonary fibrosis
}

Tomoyuki Kakugawa ${ }^{* *}$, Noriho Sakamoto', Shuntaro Sato ${ }^{2,3}$, Hirokazu Yura', Tatsuhiko Harada', Shota Nakashima', Atsuko Hara', Keishi Oda ${ }^{4}$, Hiroshi Ishimoto', Kazuhiro Yatera ${ }^{4}$, Yuji Ishimatsu ${ }^{5}$, Yasushi Obase',

Shigeru Kohno ${ }^{1}$ and Hiroshi Mukae ${ }^{1}$

\begin{abstract}
Background: Acute exacerbations of idiopathic pulmonary fibrosis are major causes of morbidity and mortality among patients with idiopathic pulmonary fibrosis. However, acute exacerbations remain unpredictable. The aim of this study was to investigate risk factors for acute exacerbations of idiopathic pulmonary fibrosis.

Methods: We performed a retrospective cohort study of patients with idiopathic pulmonary fibrosis who visited our institutions from January 1999 to September 2014. We investigated risk factors for acute exacerbations in patients with idiopathic pulmonary fibrosis diagnosed retrospectively based on the official 2011 idiopathic pulmonary fibrosis ATS/ERS/JRS/ALAT Update Statement.

Results: The idiopathic pulmonary fibrosis study cohort included 65 subjects. The median follow-up period was 2. 6 years. During follow-up, 24 patients (36.9\%) experienced acute exacerbations. A Kaplan-Meier curve demonstrated that the 1-year, 2-year, and 3-year incidences of acute exacerbation were 9.6, 19.2 and 31.0\%, respectively. Acute exacerbation exerted a significant impact on overall survival among those with the disease. A log-rank test showed that baseline cardiovascular diseases, higher GAP (gender, age, physiology) stage ( $\geq I I)$, higher serum lactate dehydrogenase level ( $\geq 180 \mathrm{U} / \mathrm{L})$, higher serum surfactant protein-D level $(\geq 194.7 \mathrm{ng} / \mathrm{mL})$, higher neutrophil $(\geq 1.77 \%)$ and eosinophil ( $\geq 3.21 \%)$ percentages in bronchoalveolar lavage fluid samples, and treatment with an immunosuppressive agent after diagnosis were associated with poor acute exacerbation-free probability. In the Cox analysis adjusted for treatment with an immunosuppressive agent, baseline cardiovascular diseases, higher GAP stage ( $\geq I I)$, and higher eosinophil percentage ( $\geq 3.21 \%)$ in bronchoalveolar lavage fluid samples were predictors of an acute exacerbation of idiopathic pulmonary fibrosis.
\end{abstract}

Conclusions: This study demonstrated that baseline cardiovascular diseases, higher GAP stage ( $\geq \|)$, and higher eosinophil percentage $(\geq 3.21 \%)$ in bronchoalveolar lavage fluid samples were associated with the onset of an acute exacerbation of idiopathic pulmonary fibrosis.

Keywords: Bronchoalveolar lavage, Krebs von den Lungen-6, Surfactant protein-D, Lactate dehydrogenase, GAP (gender, age, Physiology) stage, Cardiovascular disease

\footnotetext{
* Correspondence: kakugawa@nagasaki-u.ac.jp

'Department of Respiratory Medicine, Unit of Translational Medicine,

Nagasaki University Graduate School of Biomedical Sciences, Nagasaki, Japan

Full list of author information is available at the end of the article
} 


\section{Background}

Idiopathic pulmonary fibrosis (IPF) is the most common form of idiopathic interstitial pneumonia [1, 2], and the median survival from the time of diagnosis is approximately 3 years [2]. The clinical course of individual patients with IPF is highly variable and unpredictable. IPF is not a uniform, clinically dynamic disease; there is a wide spectrum of disease courses, including stability or slow progression over a period of years, rapid deterioration, and even periods of relative stability punctuated by events causing rapid decline [3-5]. This acute worsening of the disease is sometimes attributed to identifiable conditions such as pneumonia and heart failure. However, many of these events occur without an identifiable cause, and are called acute exacerbations (AEs) of IPF [4]. AE-IPF is a major cause of morbidity and mortality in patients with IPF [3, 6-8]. In 553 Japanese patients with IPF, the most common cause of death was $\mathrm{AE}$ with a frequency of $40 \%$ [8], which was similar to the $46 \%$ value found in a previous study by Jeon and coworkers in Korea [6]. There is no proven treatment for AE-IPF. Patients with AEs have poor outcomes, with mortality exceeding $60 \%$ during hospital admission; among those who survive, there is $>90 \%$ mortality within 6 months after discharge [3, 4]. Therefore, elucidating the pathogenesis of AE-IPF and predicting AE are important and challenging issues.

Kondoh et al. reported that a higher body mass index, higher modified Medical Research Council scale score, and decline in forced vital capacity (FVC) at 6 months after the diagnosis of IPF were independent risk factors for AE-IPF [7]. In one study, a comparison of clinical features between IPF patients with and without an AEIPF showed no difference in age, smoking status, oxygenation, or lung function at the time of diagnosis [9]. Risk factors for AE-IPF reported by Song et al. [3] include a lower FVC at baseline as well as never having smoked. Pulmonary hypertension at baseline was also reported to be associated with a significant risk of a subsequent AE-IPF [10]. More recently, Kondoh et al. reported that a rapid decline in vital capacity percentage $(\geq 10 \%$ within 6 months after the diagnosis of IPF) and high baseline alveolar-arterial difference in oxygen $\left(\mathrm{A}-\mathrm{a} \mathrm{DO}_{2}\right)$ value might be risk factors for an AE-IPF over the 52 weeks of the study [11]. However, studies regarding risk factors for AEIPF are still limited, and AEs remain unpredictable. In addition, serum biomarkers and cellular analyses of bronchoalveolar lavage (BAL) fluid are still of unclear predictive value for AE-IPF. Furthermore, in most previous studies investigating risk factors for AE-IPF, the diagnosis of IPF was made based on diagnostic criteria developed before the official IPF ATS/ERS/ JRS/ALAT Update Statement in 2011 [2].
The aim of this study was to investigate risk factors for AE-IPF, focusing on the significance of serum markers and cellular analyses of BAL fluid in patients with IPF who were diagnosed based on the official 2011 IPF ATS/ ERS/JRS/ALAT Update Statement [2].

\section{Methods \\ Study population}

We performed a retrospective cohort study of patients with IPF who visited Nagasaki University Hospital, Nagasaki, Japan, or University Hospital of Occupational and Environmental Health, Kitakyushu, Japan, from January 1999 to September 2014. Diagnoses were made retrospectively according to the official ATS/ERS/JRS/ ALAT statement [2]. Patients with underlying connective tissue disease, occupational or environmental exposure, or a histopathologic pattern on surgical lung biopsy other than usual interstitial pneumonia (UIP) were excluded from the study. At our institution, patients with suspected IPF routinely underwent bronchoscopy with BAL at the time of initial diagnosis, unless the patient's status contraindicated to the need for bronchoscopy. Patients whose initial manifestation was an $\mathrm{AE}$, patients without initial BAL fluid evaluations, and patients lost to follow-up within 90 days were excluded. Twelve of 65 $(18.5 \%)$ IPF diagnoses were confirmed pathologically in multiple lobes by open lung biopsy or video-assisted thoracoscopic surgery. AE-IPF was defined using the following previously reported criteria with a slight modification: (1) a previous diagnosis of IPF; (2) unexplained worsening of dyspnea within the past 30 days; (3) highresolution computed tomography (HRCT) with new findings of bilateral ground-glass opacity or consolidation; and (4) the absence of an alternative explanation such as infection, pulmonary embolism, pneumothorax, or heart failure $[2,4]$. The study protocol was approved by the Institutional Review Boards of Nagasaki University Hospital and University Hospital of Occupational and Environmental Health. The patients' approval or informed consent was not required for a retrospective review of their records, pursuant to the ethical guidelines of the Japanese Ministry of Health, Labor, and Welfare.

\section{Covariates}

Data regarding patient characteristics were collected from clinical notes recorded at the time of the initial diagnosis of IPF and included age, sex, smoking history, partial pressure of oxygen in arterial blood $\left(\mathrm{PaO}_{2}\right) /$ fraction of inspired oxygen $\left(\mathrm{FiO}_{2}\right)$ ratio $(\mathrm{P} / \mathrm{F}$ ratio), $\mathrm{A}-\mathrm{a} \mathrm{DO}$, hematologic data, pulmonary function tests, and BAL fluid cellular constituents. Data regarding serum concentrations of C-reactive protein (CRP), lactate dehydrogenase (LDH), Krebs von den Lungen-6 (KL-6), and surfactant protein (SP)-D were also collected from clinical 
notes recorded at the time of diagnosis. Gender-AgePhysiology (GAP) stage and composite physiologic index (CPI) were calculated as described previously $[12,13]$.

\section{BAL and cell preparation}

Bronchoscopy and BAL were performed as described previously [14].

\section{Clinical and outcome assessments}

In the $\mathrm{AE}$ analysis, subjects were censored if they (1) had not experienced an AE by September 30, 2014, or (2) were lost to follow-up. In the survival analysis, subjects were censored if they (1) were still alive on September 30, 2014, or (2) lost to follow-up. AE-free probability and survival probability were calculated from the time of the initial IPF diagnosis to censoring.

\section{Statistical analysis}

Baseline characteristics including demographics, baseline pulmonary function, respiratory parameters, hematologic data, serum markers, and BAL fluid findings were compared between patients who experienced an AE during the study period and those who did not. Data are described as frequencies for categorical variables and as the median and interquartile range (IQR) for quantitative variables. Associations between variables were assessed with Fisher's exact test for categorical variables and Wilcoxon's rank-sum test for quantitative variables. The cumulative $\mathrm{AE}$ incidence was estimated with the Kaplan-Meier method. The association between survival probability and $\mathrm{AE}$ was evaluated by the log-rank test. A log-rank test was used to evaluate associations among smoking status, cardiovascular diseases, GAP stage, biomarkers (LDH, KL-6, and SP-D), BAL fluid cellular profiles (percentages of lymphocytes, neutrophils, and eosinophils), treatment after diagnosis, and AE-free probability because the test is a simple method that did not require satisfying some assumptions. Cox's proportional hazards regression models were used to evaluate hazard ratios (HRs) and adjust confounders. It was considered appropriate to determine a cut-off level instead of using continuous data because some factors did not satisfy the assumption that the log hazard increased linearly with the covariate. The optimum cut-off values for predicting $\mathrm{AE}$ incidence at the 3-year follow-up were determined by maximizing the Youden index [15] calculated from a time-dependent receiver operating characteristic (ROC) analysis with the $\mathrm{R}$ package timeROC [16]. We reported the results at the 3-year follow-up, as this was the interval with the most dramatic relationship between biomarkers, BAL fluid cellular profiles, and AE incidence. We evaluated HRs, $95 \%$ confidence intervals (95\% CIs), and $P$ values for each factor with an unadjusted Cox analysis. Because of the small number of
AEs and deaths included in this study, it was considered inappropriate to adjust more than two factors in a multiple Cox analysis to evaluate the relative hazards of $\mathrm{AE}$ and death. Accordingly, we adjusted for treatment with an immunosuppressive agent in the multiple Cox analysis, which was found to be a significant risk factor for an AE-IPF in the log-rank test and unadjusted Cox analysis in this study. All tests were two-sided, and a $P$ value less than 0.05 was considered statistically significant. All statistical analyses were performed using SAS version 9.4 (SAS Institute Inc., Cary, NC, USA) and $R$ version 3.1.0.

\section{Results}

\section{Subject characteristics}

The IPF study cohort included 65 subjects. There were 51 men and 14 women with a median age of 69 years (IQR, 62 to 73 years). There were 13 never smokers, 42 former smokers, and 10 current smokers. The median follow-up period was 2.6 years (IQR, 1.3 to 4.2 years). The median survival time (MST) for all subjects was 4.5 years from the time of the initial visit.

\section{AE incidence}

During the follow-up period, 24 patients (36.9\%) experienced AEs. Eighteen patients $(27.7 \%)$ were lost to follow-up. The Kaplan-Meier curve demonstrated that the 1-year, 2-year, and 3-year incidences of AE-IPF were 9.6, 19.2 and $31.0 \%$, respectively (Fig. 1).

\section{Demographic, physiological, gas exchange, and laboratory data and BAL fluid findings between patients with an AE (AE group) and those without an AE (Non-AE group)}

No significant differences were observed in sex or age distributions between the groups. Patients who experienced an AE had a lower total lung capacity than those in the Non-AE group. Gas exchange and laboratory data and BAL fluid findings were similar between the groups (Table 1).

\section{Impact of AE on overall survival}

$\mathrm{AE}$ exerted a significant impact on overall survival in IPF. There was a significant difference in survival between patients who experienced an AE (MST, 2.8 years) and those who did not (MST, not calculable) (log-rank test, $P<0.001)$ (Fig. 2).

\section{Risk factors for $\mathrm{AE}$}

According to the ROC curve analysis, the optimum cutoff levels to predict an AE-IPF were $180 \mathrm{U} / \mathrm{L}$ for LDH, $946 \mathrm{U} / \mathrm{mL}$ for KL-6, $194.7 \mathrm{ng} / \mathrm{mL}$ for SP-D; and 10.15 1.77 and $3.21 \%$ for lymphocyte, neutrophil, and eosinophil percentages in BAL fluid samples, respectively. A 


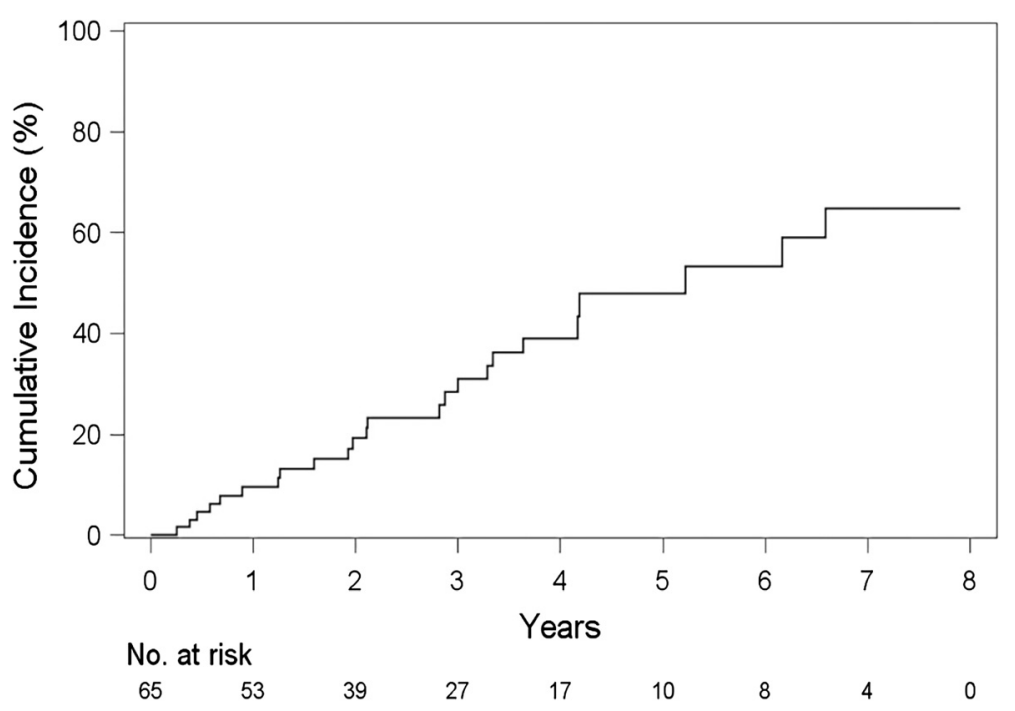

Fig. 1 Incidence of acute exacerbation of idiopathic pulmonary fibrosis. The Kaplan-Meier curve demonstrates that the 1-year, 2-year, and 3-year incidences of AE-IPF were 9.6, 19.2 and $31.0 \%$, respectively

log-rank test showed that baseline cardiovascular diseases, higher GAP stage ( $\geq \mathrm{II})$, higher serum LDH level $(\geq 180 \mathrm{U} / \mathrm{L})$, higher serum SP-D level $(\geq 194.7 \mathrm{ng} / \mathrm{mL})$, higher neutrophil $(\geq 1.77 \%)$ and eosinophil $(\geq 3.21 \%)$ percentages in BAL fluid samples, and treatment with an immunosuppressive agent after diagnosis were associated with poor AE-free probability $(P=0.042,0.002$, $0.048,0.014,0.048,0.009$, and 0.009 , respectively) (Table 2). In the unadjusted Cox analysis, treatment with an immunosuppressive agent, baseline cardiovascular diseases, higher GAP stage ( $\geq \mathrm{II})$, higher serum SP-D level ( $\geq 194.7 \mathrm{ng} / \mathrm{mL})$, and a higher eosinophil percentage in BAL fluid samples $(\geq 3.21 \%)$ were predictors of an AEIPF (HR [95 \% CI], 3.35 [1.27-8.84], 2.49 [1.00-6.19], 3.88 [1.54-9.80], 3.17 [1.21-8.31], and 3.27 [1.29-8.29], respectively). In the Cox analysis adjusted for treatment with an immunosuppressive agent, baseline cardiovascular diseases, higher GAP stage ( $\geq \mathrm{II})$, and higher eosinophil percentage $(\geq 3.21 \%)$ in BAL fluid samples were predictors of an AE-IPF (HR [95 \% CI], 3.21 [1.24-8.32], 3.23 [1.22-8.51], and 2.89 [1.11-7.51], respectively) (Table 3).

\section{Prognostic factors for overall survival from the initial IPF diagnosis}

In the unadjusted Cox analysis, higher baseline GAP stage ( $\geq \mathrm{II})$, higher serum SP-D level $(\geq 194.7 \mathrm{ng} / \mathrm{mL})$, and higher eosinophil percentage $(\geq 3.21 \%)$ in BAL fluid samples were significant prognostic factors for IPF (HR [95 \% CI], 4.02 [1.68-9.64], 3.49 [1.36-8.94], and 2.42 [1.03-5.68], respectively). In the Cox analysis adjusted for treatment with an immunosuppressive agent, baseline cardiovascular diseases, higher GAP stage $(\geq \mathrm{II})$, and higher serum SP-D level $(\geq 194.7 \mathrm{ng} / \mathrm{mL})$ were significant prognostic factors for IPF (HR [95 \% CI], 2.37 [1.03-5.44], 3.63 [1.47-8.93], and 3.21 [1.21-8.48]) (Table 4).

\section{Discussion}

This study examined associations between patient characteristics, serum markers, and BAL fluid cellular constituents and the incidence of AE-IPF and survival in a cohort of IPF patients who were diagnosed based on the official 2011 IPF ATS/ERS/JRS/ALAT Update Statement [2]. A log-rank test showed that treatment with an immunosuppressive agent after diagnosis, baseline cardiovascular diseases, higher GAP stage $(\geq \mathrm{II})$, higher serum LDH level $(\geq 180$ U/L), higher serum SP-D level $(\geq 194.7 \mathrm{ng} / \mathrm{mL})$, and higher neutrophil $(\geq 1.77 \%)$ and eosinophil $(\geq 3.21 \%)$ percentages in BAL fluid samples were associated with poor AE-free probability. In the Cox analysis adjusted for treatment with an immunosuppressive agent, baseline cardiovascular diseases, higher GAP stage $(\geq \mathrm{II})$, and a higher eosinophil percentage $(\geq 3.21 \%)$ in BAL fluid samples were predictors of an AE-IPF.

It was reported that the human lung microbiome and any changes in its numbers and composition play important roles in the pathogenesis and progression of lung diseases, including IPF $[17,18]$. In addition, it was recently reported that patients with IPF had a higher bacterial load in BAL fluid compared with control subjects and that an increased bacterial load at the time of diagnosis identified patients with more rapidly progressive IPF and those at a higher risk of mortality [19]. The multicenter PANTHER trial found that combination therapy (prednisone, azathioprine, and $\mathrm{N}$-acetylcysteine) was associated with more AEs than a placebo. [20]. The 
Table 1 Comparisons of baseline characteristics between patients with and without an acute exacerbation

\begin{tabular}{|c|c|c|c|c|c|}
\hline & $\begin{array}{l}\text { Non-AE } \\
(N=41)\end{array}$ & & $\begin{array}{l}\mathrm{AE} \\
(N=24)\end{array}$ & & $P$ Value $^{a}$ \\
\hline Age, median (IQR), y & 69.0 & (62.0 to 73.0$)$ & 68.0 & (62.0 to 73.5$)$ & 0.995 \\
\hline \multicolumn{6}{|l|}{ Sex, No. (\%) } \\
\hline Men & 31 & $(75.6)$ & 20 & $(83.3)$ & \multirow[t]{2}{*}{1.000} \\
\hline Women & 10 & $(24.4)$ & 4 & $(16.7)$ & \\
\hline \multicolumn{6}{|l|}{ Smoking, No. (\%) } \\
\hline S & 7 & $(17.1)$ & 3 & $(12.5)$ & \multirow[t]{3}{*}{1.000} \\
\hline Ex & 25 & $(61.0)$ & 17 & $(70.8)$ & \\
\hline N & 9 & $(22.0)$ & 4 & $(16.7)$ & \\
\hline Smoking index, pack-years & 35.8 & (1.0 to 52.3 ) & 31.3 & (15.0 to 50.0$)$ & 0.940 \\
\hline \multicolumn{6}{|l|}{ Cardiovascular diseases, №. (\%) } \\
\hline Yes & 10 & $(24.4)$ & 8 & $(33.3)$ & \multirow[t]{2}{*}{1.000} \\
\hline No & 31 & $(75.6)$ & 16 & $(66.7)$ & \\
\hline \multicolumn{6}{|l|}{ Atopic diseases, No. (\%) } \\
\hline Yes & 3 & $(7.3)$ & 1 & $(4.2)$ & \multirow[t]{2}{*}{1.000} \\
\hline No & 38 & $(92.7)$ & 23 & $(95.8)$ & \\
\hline \multicolumn{6}{|l|}{ Baseline pulmonary function } \\
\hline VC, median (IQR), \% predicted & 81.0 & (64.1 to 95.0$)$ & 69.2 & (59.5 to 83.0$)$ & 0.074 \\
\hline FVC, median (IQR), \% predicted & 80.4 & (59.0 to 93.9$)$ & 70.5 & (59.9 to 82.1$)$ & 0.055 \\
\hline TLC, median (IQR), \% predicted & 75.9 & (63.0 to 90.0$)$ & 66.1 & (54.0 to 77.0$)$ & 0.020 \\
\hline DLCO, median (IQR), \% predicted & 58.0 & (46.1 to 72.5$)$ & 46.2 & (41.0 to 72.3$)$ & 0.276 \\
\hline KCO, median (IQR), \% predicted & 69.5 & (60.8 to 85.0$)$ & 73.0 & (57.7 to 78.0$)$ & 0.866 \\
\hline \multicolumn{6}{|l|}{ GAP stage, No. (\%) } \\
\hline । & 25 & $(69.4)$ & 10 & $(45.5)$ & \multirow[t]{3}{*}{1.000} \\
\hline$\|$ & 9 & $(25.0)$ & 12 & $(54.5)$ & \\
\hline III & 2 & $(5.6)$ & 0 & $(0.0)$ & \\
\hline $\mathrm{CPI}$ & 37.3 & (22.2 to 47.6$)$ & 47.7 & (30.5 to 54.9$)$ & 0.190 \\
\hline \multicolumn{6}{|l|}{ Respiratory parameters ${ }^{b}$} \\
\hline $\mathrm{PaO}_{2}$, median (IQR), $\mathrm{mm} \mathrm{Hg}$ & 80.7 & (75.3 to 91.0$)$ & 81.0 & (75.2 to 94.5$)$ & 0.810 \\
\hline A-a $\mathrm{DO}_{2}$, median (IQR), mm Hg & 17.5 & (3.8 to 26.2 ) & 17.2 & (4.1 to 25.2 ) & 0.889 \\
\hline \multicolumn{6}{|l|}{ Hematologic data } \\
\hline WBC, median (IQR), $/ \mathrm{mm}^{3}$ & 6700 & (5800 to 8100$)$ & 7350 & (5750 to 9300$)$ & 0.442 \\
\hline Neutrophils, median (IQR), \% & 62.8 & (57.0 to 69.4$)$ & 63.9 & (58.0 to 69.0$)$ & 0.897 \\
\hline Eosinophils, median (IQR), \% & 3.0 & (2.0 to 4.7$)$ & 2.9 & (1.8 to 4.4$)$ & 0.545 \\
\hline \multicolumn{6}{|l|}{ Serum markers } \\
\hline CRP, median (IQR), mg/dL & 0.31 & (0.06 to 0.69$)$ & 0.29 & (0.13 to 0.64$)$ & 0.688 \\
\hline LDH, median (IQR), U/L & 235 & (187.0 to 255.0$)$ & 247 & (223.5 to 296.0$)$ & 0.082 \\
\hline $\mathrm{KL}-6$, median (IQR), U/mL & 912 & (595.0 to 1802.0$)$ & 1258 & (744.5 to 2006.0) & 0.246 \\
\hline SP-D, median (IQR), $\mathrm{ng} / \mathrm{mL}$ & 203 & (131.0 to 342.0$)$ & 269 & (178.6 to 343.0$)$ & 0.285 \\
\hline \multicolumn{6}{|l|}{ BAL fluid findings } \\
\hline Total cell count, median (IQR), $\times 10^{5} / \mathrm{mL}$ & 2.50 & $(1.40$ to 3.67$)$ & 3.21 & (2.22 to 3.97$)$ & 0.099 \\
\hline Macrophages, median (IQR), \% & 80.2 & $(62.5$ to 88.9$)$ & 76.6 & (67.3 to 84.8$)$ & 0.492 \\
\hline Lymphocytes, median (IQR), \% & 6.8 & (3.9 to 11.4 ) & 11.6 & (3.2 to 17.1 ) & 0.649 \\
\hline
\end{tabular}


Table 1 Comparisons of baseline characteristics between patients with and without an acute exacerbation (Continued)

\begin{tabular}{|c|c|c|c|c|c|}
\hline Neutrophils, median (IQR), \% & 6.7 & (2.9 to 13.3$)$ & 7.0 & (3.2 to 10.5$)$ & 0.807 \\
\hline Eosinophils, median (IQR), \% & 3.3 & $(1.2$ to 5.4$)$ & 4.6 & $(2.1$ to 7.0$)$ & 0.259 \\
\hline CD4/8 ratio, median (IQR) & 1.90 & (0.86 to 3.70$)$ & 1.10 & (0.60 to 1.90$)$ & 0.065 \\
\hline \multicolumn{6}{|l|}{ Treatment after the diagnosis } \\
\hline \multicolumn{6}{|l|}{ Steroid, No. (\%) } \\
\hline yes & 7 & $(17.1)$ & 8 & $(33.3)$ & 1.000 \\
\hline No & 34 & $(82.9)$ & 16 & $(66.7)$ & \\
\hline \multicolumn{6}{|c|}{ Immunosuppressive agent ${ }^{\mathrm{C}}$, No. (\%) } \\
\hline Yes & 3 & $(7.3)$ & 6 & $(25.0)$ & 1.000 \\
\hline No & 38 & $(92.7)$ & 18 & $(75.0)$ & \\
\hline \multicolumn{6}{|c|}{ Steroid with immunosuppressive agent, №. (\%) } \\
\hline Yes & 3 & $(7.3)$ & 5 & $(20.8)$ & 1.000 \\
\hline No & 38 & $(92.7)$ & 19 & $(79.2)$ & \\
\hline \multicolumn{6}{|l|}{ Pirfenidone, No. (\%) } \\
\hline Yes & 8 & $(19.5)$ & 6 & $(25.0)$ & 1.000 \\
\hline No & 33 & $(80.5)$ & 18 & $(75.0)$ & \\
\hline \multicolumn{6}{|l|}{ NAC, No. (\%) } \\
\hline Yes & 8 & $(19.5)$ & 5 & $(20.8)$ & 1.000 \\
\hline No & 33 & $(80.5)$ & 19 & $(79.2)$ & \\
\hline
\end{tabular}

Abbreviations: $A E$ acute exacerbation, $N$ number of patients, IQR interquartile range, $S / E x / N$ current smoker/ex-smoker/nonsmoker, $V C$ vital capacity, FVC forced vital capacity, $T L C$ total lung capacity, DLCO diffusing capacity for carbon monoxide, $K C O$ carbon monoxide transfer coefficient, GAP gender-age-physiology, CPI composite physiologic index, $\mathrm{P} / \mathrm{F}$ ratio $\mathrm{PaO}_{2}$ /fraction of inspired oxygen ratio, $A-a D O_{2}$ alveolar-arterial difference in oxygen, WBC white blood cell count, $C R P$ C-reactive protein, $L D H$ lactate dehydrogenase, $K L-6$ Krebs von den Lungen-6, SP-D surfactant protein- $D$, $B A L$ bronchoalveolar lavage, $C D 4 / 8$ ratio CD4/CD8 lymphocyte subset ratio, NAC inhaled N-acetylcysteine Data are presented as the median (interquartile range)

a'Wilcoxon's rank-sum test was performed for continuous variables, and Fisher's exact test was performed for categorical variables

bone patient in the Non-AE group required oxygen $\left(1 \mathrm{~L} / \mathrm{min} \mathrm{O}_{2}\right.$ via a nasal cannula) at the time of sample collection. All other results were obtained at room air

Immunosuppressive agents included cyclosporine $(N=7)$ and cyclophosphamide $(N=2)$

present study also demonstrated that treatment with an immunosuppressive agent was associated with an AEIPF in the log-rank test and unadjusted Cox analysis. In addition, Papiris et al. recently reported that immunosuppression adversely affected the outcomes of AE-IPFs [21]. These findings imply that treatment with an immunosuppressive agent may increase the bacterial load in the lungs of patients with IPF and lead to an AE-IPF. Further studies are needed to elucidate the association between bacterial load and AE-IPFs. However, baseline cardiovascular diseases, higher GAP stage $(\geq \mathrm{II})$, and higher eosinophil percentage $(\geq 3.21 \%)$ in BAL fluid samples were predictors of an AE-IPF, even after adjustment for treatment with an immunosuppressive agent in the Cox analysis. These risk factors were thought to be independent of treatment with an immunosuppressive agent.

BAL fluid analyses in IPF patients typically show an increase in total cell count, neutrophils $(>5 \%)$, and eosinophils $(>5 \%)$ [22]. In the present study, baseline median neutrophil and eosinophil percentages in the BAL fluid of patients who experienced an AE were $7.0 \%$ (IQR: $3.2-10.5 \%$ ) and $4.6 \%$ (IQR: $2.1-7.0 \%$ ), respectively.
These BAL fluid findings were consistent with those previously reported in patients with IPF [22]. This study showed that higher neutrophil $(\geq 1.77 \%)$ and eosinophil $(\geq 3.21 \%)$ percentages in BAL fluid samples were associated with poor AE-free probability in the log-rank test. In the adjusted Cox analysis, a higher baseline eosinophil percentage $(\geq 3.21 \%)$ in BAL fluid samples was a predictor of an AE-IPF. Relative increases in eosinophil and neutrophil percentages in BAL fluid may identify a subset of patients with disease that is more "active" or in an accelerated phase of tissue damage that may predispose them to an AE. Although inflammation is never a prominent histopathological finding in UIP [2], occult sustained eosinophil and neutrophil accumulations in the alveolar space may be key immune effector cells driving the inflammatory response and may play a role in the occurrence of an AE-IPF. Findings of recent studies of high BAL fluid eosinophil and neutrophil percentages in patients with IPF during AEs lend support to this possibility [3, 9]. Tabuena et al. [23] found that BAL fluid neutrophil and lymphocyte counts predicted mortality in current smokers in a study of 81 patients with IPF. Kinder et al. recently reported that each doubling of 


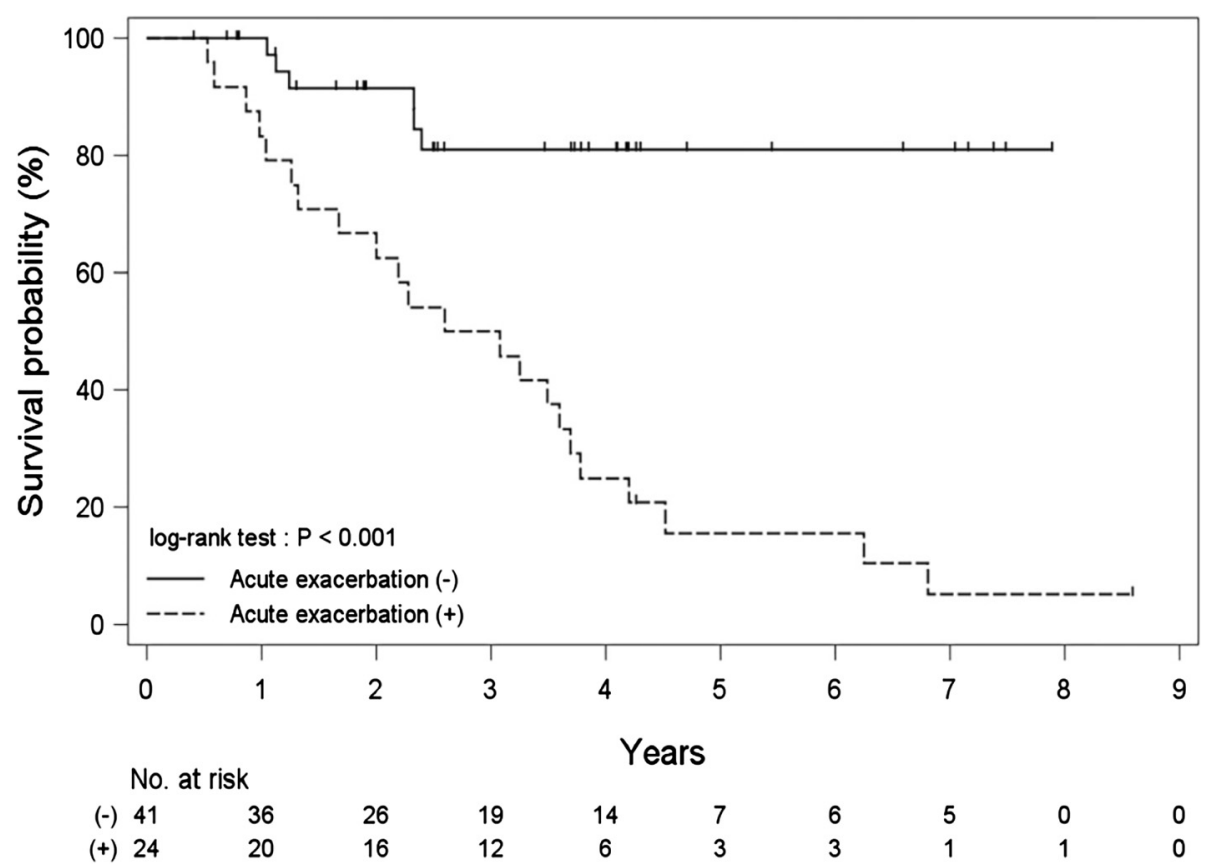

Fig. 2 Impact of acute exacerbation on overall survival. There was a significant difference in survival between patients who experienced an acute exacerbation (median survival time, 2.8 years) and those who did not (median survival time, not calculable) (log-rank test, $P<0.001$ )

baseline BAL fluid neutrophil percentage was associated with a $30 \%$ increase in mortality risk in a series of 156 patients with biopsy-proven IPF [24]. These observations also suggest the potential contribution of inflammation in the pathogenesis of IPF. Although the possible role of a chronic inflammatory response has been largely neglected because of the inefficacy of corticosteroids and immunosuppressants in the treatment of IPF $[2,20]$, further studies focusing on the potential role of inflammation in IPF pathogenesis and AE-IPF occurrence are needed. Current practice and consensus guidelines [2] do not recommend performing BAL for a determination of cellular constituents in BAL fluid at the time of IPF diagnosis. However, the indication for BAL with a cellular analysis may become clearer when effective therapies to prevent an AE-IPF are discovered.

This study showed that a baseline higher GAP stage ( $\geq \mathrm{II})$ was one of the predictors of an AE-IPF and a significant prognostic factor for IPF in the adjusted Cox analysis. This GAP model consists of four baseline variables: gender $(\mathrm{G})$, age $(\mathrm{A})$, and two lung physiology variables (P) (FVC and diffusing capacity for carbon monoxide) [12]. It has been proposed that the GAP model was useful in the prediction of mortality at baseline in patients with IPF [12]. In addition, it was reported that GAP stage III IPF patients tended to have a higher incidence of AEs than stage II and stage I patients [25]. The present findings along with those obtained in previous studies suggest that the GAP staging system could be used as a quick and simple screening method for predicting AE-IPF.

Cardiovascular disease has been reported to be one of the most frequently observed comorbidities in patients with IPF and associated with shortened survival time $[26,27]$. However, the impact on AE-IPF has remained unknown. This study showed that baseline cardiovascular disease was not only a prognostic factor for IPF, but also a risk factor for an AE-IPF in the adjusted Cox analysis. Further studies are needed to elucidate the mechanisms of why cardiovascular disease increases the risk of AE-IPF.

SP-D is a lipoprotein complex synthesized mainly by alveolar type II epithelial cells and is secreted into a liquid layer lining the lung epithelium. Increased serum SP-D levels obtained at the time of IPF diagnosis were reported to be associated with increased mortality [28-30]. In the present study, serum SP-D levels obtained at the time of initial diagnosis were associated with AE-free probability in a log-rank test and overall survival in the adjusted Cox analysis. Two mechanisms may contribute to elevated SP-D serum levels in pulmonary fibrosis: (1) an absolute increase in alveolar type II epithelial cells due to diffuse hyperplasia increases at the source of pulmonary SP-D; and (2) epithelial injury and basal membrane leakage may cause spillover into the circulation [28]. Evidence indicates that repetitive injuries to alveolar epithelial cells trigger an exaggerated wound healing response resulting in extensive scar formation, 
Table 2 Log-rank test for risk factors for an acute exacerbation of idiopathic pulmonary fibrosis

\begin{tabular}{|c|c|c|c|}
\hline & Non-AE $(N=41)$ & $\mathrm{AE}(N=24)$ & log-rank $P$ Value \\
\hline \multicolumn{4}{|l|}{ Smoking } \\
\hline S or Ex & 32 & 20 & 0.918 \\
\hline N & 9 & 4 & \\
\hline \multicolumn{4}{|c|}{ Cardiovascular diseases } \\
\hline Yes & 10 & 8 & 0.042 \\
\hline No & 31 & 16 & \\
\hline \multicolumn{4}{|l|}{ GAP stage } \\
\hline \| or III & 11 & 12 & 0.002 \\
\hline I & 25 & 10 & \\
\hline \multicolumn{4}{|c|}{ Serum markers } \\
\hline \multicolumn{4}{|l|}{ LDH } \\
\hline$\geq 180$ & 32 & 22 & 0.048 \\
\hline$<180$ & 9 & 2 & \\
\hline \multicolumn{4}{|l|}{$\mathrm{KL}-6$} \\
\hline$\geq 946$ & 18 & 16 & 0.292 \\
\hline$<946$ & 21 & 8 & \\
\hline \multicolumn{4}{|l|}{ SP-D } \\
\hline$\geq 194.7$ & 22 & 18 & 0.014 \\
\hline$<194.7$ & 17 & 6 & \\
\hline
\end{tabular}

BAL fluid findings

Lymphocytes

$\begin{array}{lll}\geq 10.15 & 13 & 1 \\ <10.15 & 28 & 1\end{array}$

Neutrophils

$\geq 1.77 \quad 34$

$<1.77 \quad 7$

Eosinophils

$$
\geq 3.21 \quad 21
$$$$
<3.21 \quad 20
$$

Treatment after the diagnosis

Steroid

$\begin{array}{ll}\text { Yes } & 7 \\ \text { No } & 34\end{array}$

Immunosuppressive agent

$\begin{array}{llll}\text { Yes } & 3 & 6 & 0.009 \\ \text { No } & 38 & 18 & \\ \text { Pirfenidone } & & & 0.963 \\ \text { Yes } & 8 & 18 & \\ \text { No } & 33 & 5 & 0.547 \\ \text { NAC } & & 19 & \\ \text { Yes } & 8 & 33 & \end{array}$

Abbreviations: $A E$ acute exacerbation, $N$ number of patients, $S / E x / N$ current smoker/ex-smoker/nonsmoker, GAP gender-age-physiology, $L D H$ lactate dehydrogenase, $K L-6$ Krebs von den Lungen-6, SP-D surfactant protein-D, $B A L$ bronchoalveolar lavage, NAC inhaled $\mathrm{N}$-acetylcysteine
Table 3 Cox analysis for risk factors for an acute exacerbation of idiopathic pulmonary fibrosis

\begin{tabular}{|c|c|c|c|}
\hline & $\mathrm{HR}$ & $(95 \% \mathrm{Cl})$ & $P$ Value \\
\hline \multicolumn{4}{|c|}{ Treatment after the diagnosis } \\
\hline \multicolumn{4}{|c|}{ Immunosuppressive agent } \\
\hline Unadjusted & 3.35 & (1.27 to 8.84$)$ & 0.014 \\
\hline \multicolumn{4}{|c|}{ Cardiovascular diseases } \\
\hline Unadjusted & 2.49 & (1.00 to 6.19$)$ & 0.049 \\
\hline Adjusted $^{\mathrm{a}}$ & 3.21 & (1.24 to 8.32$)$ & 0.016 \\
\hline \multicolumn{4}{|l|}{ GAP stage $(\geq I I)$} \\
\hline Unadjusted & 3.88 & (1.54 to 9.80$)$ & 0.004 \\
\hline Adjusted $^{\mathrm{a}}$ & 3.23 & (1.22 to 8.51$)$ & 0.018 \\
\hline
\end{tabular}

Serum markers

$L D H, U / L$, Cut off point $=180$

\begin{tabular}{|c|c|c|c|}
\hline Unadjusted & 4.00 & (0.92 to 17.46$)$ & 0.065 \\
\hline Adjusted $^{a}$ & 3.49 & (0.78 to 15.57$)$ & 0.101 \\
\hline \multicolumn{4}{|c|}{$\mathrm{L}-6, \mathrm{U} / \mathrm{mL}$, Cut off point $=946$} \\
\hline Unadjusted & 1.57 & (0.67 to 3.68$)$ & 0.296 \\
\hline Adjusted $^{\mathrm{a}}$ & 1.53 & (0.65 to 3.59$)$ & 0.326 \\
\hline \multicolumn{4}{|c|}{ P-D, ng/mL, Cut off point $=194.7$} \\
\hline Unadjusted & 3.17 & (1.21 to 8.31$)$ & 0.019 \\
\hline Adjusted $^{\mathrm{a}}$ & 2.69 & (0.98 to 7.42$)$ & 0.056 \\
\hline
\end{tabular}

BAL fluid findings

Lymphocytes, \%, Cut off point $=10.15$

$\begin{array}{llll}\text { Unadjusted } & 2.01 & \text { (0.89 to } 4.52) & 0.091 \\ \text { Adjusted }^{a} & 2.03 & (0.90 \text { to } 4.57) & 0.087\end{array}$

Neutrophils, \%, Cut off point $=1.77$

$\begin{array}{llll}\text { Unadjusted } & 4.04 & \text { (0.92 to 17.79) } & 0.065 \\ \text { Adjusted }^{\mathrm{a}} & 3.54 & \text { (0.79 to 15.94) } & 0.100\end{array}$

Eosinophils, \%, Cut off point $=3.21$

$\begin{array}{llll}\text { Unadjusted } & 3.27 & (1.29 \text { to } 8.29) & 0.013 \\ \text { Adjusted }^{a} & 2.89 & (1.11 \text { to } 7.51) & 0.029\end{array}$

Abbreviations: $H R$ hazard ratio, $\mathrm{Cl}$ confidence interval, GAP gender-agephysiology, $L D H$ lactate dehydrogenase, $K L-6$ Krebs von den Lungen-6, SP-D surfactant protein-D, BAL bronchoalveolar lavage

${ }^{a}$ Adjusted for immunosuppressive agent therapy

and finally, pulmonary fibrosis [31, 32]. Together with previous observations, the present findings suggest that injuries to alveolar epithelial cells may be one of the important triggers for IPF progression.

In a randomized trial of pirfenidone, a positive treatment effect was demonstrated, including fewer AE-IPF episodes (14\% versus none) [33]. However, a previous study did not reproduce the inhibitory effect of pirfenidone on AE-IPF [34]. In the present study, neither treatment with pirfenidone nor $\mathrm{N}$-acetylcysteine was associated with AE-free probability in a log-rank test. However, this might be due to the small number of patients treated with pirfenidone or NAC in this study. 
Table 4 Cox analysis for prognostic factors for overall survival from the idiopathic pulmonary fibrosis initial diagnosis

\begin{tabular}{|c|c|c|c|}
\hline & $\mathrm{HR}$ & $(95 \% \mathrm{Cl})$ & $P$ Value \\
\hline \multicolumn{4}{|c|}{ Treatment after diagnosis } \\
\hline \multicolumn{4}{|c|}{ Immunosuppressive agent } \\
\hline Unadjusted & 2.40 & (0.96 to 6.02$)$ & 0.062 \\
\hline \multicolumn{4}{|c|}{ Cardiovascular diseases } \\
\hline Unadjusted & 2.08 & (0.91 to 4.54$)$ & 0.086 \\
\hline Adjusted $^{\mathrm{a}}$ & 2.37 & (1.03 to 5.44$)$ & 0.042 \\
\hline \multicolumn{4}{|l|}{ GAP stage $(\geq I I)$} \\
\hline Unadjusted & 4.02 & (1.68 to 9.64$)$ & 0.002 \\
\hline Adjusted $^{a}$ & 3.63 & (1.47 to 8.93$)$ & 0.005 \\
\hline \multicolumn{4}{|l|}{ Serum markers } \\
\hline \multicolumn{4}{|c|}{ LDH, U/L, Cut off point $=180$} \\
\hline Unadjusted & 2.49 & (0.74 to 8.37$)$ & 0.139 \\
\hline Adjusted $^{a}$ & 2.24 & (0.66 to 7.63$)$ & 0.198 \\
\hline \multicolumn{4}{|c|}{$\mathrm{KL}-6, \mathrm{U} / \mathrm{mL}$, Cut off point $=946$} \\
\hline Unadjusted & 1.46 & (0.67 to 3.18$)$ & 0.340 \\
\hline Adjusted $^{a}$ & 1.45 & (0.67 to 3.17$)$ & 0.345 \\
\hline \multicolumn{4}{|c|}{ SP-D, ng/mL, Cut off point $=194.7$} \\
\hline Unadjusted & 3.49 & (1.36 to 8.94$)$ & 0.009 \\
\hline Adjusted $^{a}$ & 3.21 & (1.21 to 8.48$)$ & 0.019 \\
\hline \multicolumn{4}{|c|}{ BAL fluid findings } \\
\hline \multicolumn{4}{|c|}{ Lymphocytes, \%, Cut off point $=10.15$} \\
\hline Unadjusted & 1.96 & (0.93 to 4.14$)$ & 0.077 \\
\hline Adjusted $^{\mathrm{a}}$ & 1.99 & (0.94 to 4.21$)$ & 0.072 \\
\hline \multicolumn{4}{|c|}{ Neutrophils, \%, Cut off point = 1.77} \\
\hline Unadjusted & 2.48 & (0.73 to 8.45$)$ & 0.147 \\
\hline Adjusted $^{a}$ & 2.21 & (0.63 to 7.69$)$ & 0.213 \\
\hline \multicolumn{4}{|c|}{ Eosinophils, \%, Cut off point = 3.21} \\
\hline Unadjusted & 2.42 & (1.03 to 5.68$)$ & 0.043 \\
\hline Adjusted $^{a}$ & 2.20 & (0.92 to 5.25$)$ & 0.075 \\
\hline
\end{tabular}

Abbreviations: $H R$ hazard ratio, $\mathrm{Cl}$ confidence interval, GAP gender-agephysiology, $L D H$ lactate dehydrogenase, $K L-6$ Krebs von den Lungen-6, SP-D surfactant protein-D, BAL bronchoalveolar lavage

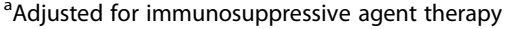

Whether new antifibrotic agents have preventive effects against AE-IPF is an interesting clinical question. Further studies are needed to elucidate this question.

Previously reported conflicting results regarding risk factors for an AE-IPF were probably partly related to the use of multiple AE-IPF definitions. According to previously reported AE-IPF criteria, endotracheal aspirate or BAL fluid should be examined to exclude pulmonary infection, and patients who do not undergo these procedures should be termed as having a "suspected AE" [4]. However, these procedures are often not feasible given the significant hypoxemia typical in an AE-IPF. There is a frequent inability to exclude underlying infection results confidently in a large number of "suspected" AEIPF cases that cannot be confirmed. Therefore, the definition of AE-IPF in the present study did not include the performance of endotracheal aspirate collection or BAL as an essential component. Collard et al. recently reported that suspected AE-IPF cases were clinically indistinguishable from definite AE-IPF cases, and were associated with similarly high risks of disease progression and short-term mortality in IPF [35]. Ryerson et al. recently proposed expanding the AE-IPF diagnostic criteria by allowing the diagnostic criteria to be met without the performance of invasive procedures (e.g. bronchoscopy) [36]. In fact, the definition of AE-IPF used in recent clinical trials of nintedanib did not include the performance of endotracheal aspirate collection or BAL as essential components, and infection was excluded in accordance with routine clinical practice and microbiologic studies [37]. Therefore, the results obtained in the present study are thought to be practical for the management of patients with IPF in daily clinical settings.

There are some limitations to this study. First, this was a retrospective study with a small number of subjects. Because of the small numbers of AEs and deaths, risk factors and prognostic factors were adjusted only by treatment with an immunosuppressive agent in the multiple Cox analysis. Because the associations among several factors seem to be complex, further study in a larger patient cohort is needed to analyze independent risk factors for AE-IPF and prognostic factors for IPF. Second, although the present study suggests that alveolar inflammation may be one of the key pathways activated prior to the development of an AE-IPF, the precise biological mechanisms of AE-IPF remain unknown. Third, this study included only Japanese patients. Therefore, further studies are needed to ascertain whether these results can be applied equally to other ethnic groups. The relative rarity of AE-IPF suggests that these research questions should be answered by multicenter collaborations.

\section{Conclusions}

In conclusion, this study demonstrated that baseline cardiovascular diseases, higher GAP stage $(\geq \mathrm{II})$, and higher eosinophil percentage $(\geq 3.21 \%)$ in BAL fluid samples were predictors of an AE-IPF. Further studies are needed to elucidate the association between these markers and mechanisms of AE occurrence.

\section{Abbreviations}

$\mathrm{A}$-a $\mathrm{DO}_{2}$, alveolar-arterial difference in oxygen; $\mathrm{AE}$, acute exacerbation; $\mathrm{BAL}$, bronchoalveolar lavage; $\mathrm{Cl}$, confidence interval; $\mathrm{CPI}$, composite physiologic index; CRP, C-reactive protein; DLCO, diffusing capacity for carbon monoxide; $\mathrm{FiO}_{2}$, fraction of inspired oxygen; FVC, forced vital capacity; GAP, gender-agephysiology; HR, hazard ratio; HRCT, high-resolution computed tomography; IPF, idiopathic pulmonary fibrosis; IQR, interquartile range; $\mathrm{KCO}$, carbon 
monoxide transfer coefficient; KL-6, Krebs von den Lungen-6; LDH, lactate dehydrogenase; MST, median survival time; NAC, N-acetylcysteine; P/F ratio, partial pressure of oxygen in arterial blood $\left(\mathrm{PaO}_{2}\right) /$ fraction of inspired oxygen $\left(\mathrm{FiO}_{2}\right)$ ratio; $\mathrm{PaO}_{2}$, partial pressure of oxygen in arterial blood; $\mathrm{ROC}$, receiver operating characteristic; SP-D, surfactant protein-D; UIP, usual interstitial pneumonia

\section{Acknowledgments}

The authors thank Dr. M. Kitaichi (Department of Laboratory Medicine and Pathology, NHO Kinki-chuo Chest Medical Center, Sakai, Japan) for valuable advice regarding pathological diagnosis, and Mr. A. Yokoyama and Mr. A. Nishigaki for excellent technical support. We would like to thank Editage (www.editage.jp) for English language editing.

\section{Funding}

This study was supported in part by a research grant from Takeda Science Foundation and Grants-in-Aid for Scientific Research of Japan Society for the Promotion of Science (JSPS KAKENHI), grant numbers 25860649 and 15 K09223.

\section{Availability of data and materia}

The data will not be shared with participant confidentiality.

\section{Authors' contributions}

TK made substantial contributions to the study conception and design. SS participated in the design of the study and performed the statistical analysis. $\mathrm{TK}, \mathrm{NS}, \mathrm{HU}, \mathrm{TH}, \mathrm{SN}, \mathrm{AH}, \mathrm{KO}, \mathrm{HI}, \mathrm{KY}, \mathrm{Yl}$, and $\mathrm{YO}$ collected the clinical data from clinical notes and retrospectively made diagnoses of idiopathic pulmonary fibrosis. TK drafted the article. SK and HM critically revised the article for important intellectual content. All authors read and approved the final manuscript.

\section{Competing interests}

The authors declare that they have no competing interests.

\section{Consent for publication}

Not applicable.

\section{Ethics approval and consent to participate}

The study protocol was approved by the Institutional Review Boards of Nagasaki University Hospital and University Hospital of Occupational and Environmental Health. The patients' approval or informed consent was not required for a retrospective review of their records, pursuant to the ethical guidelines of the Japanese Ministry of Health, Labor, and Welfare.

\section{Author details}

${ }^{1}$ Department of Respiratory Medicine, Unit of Translational Medicine, Nagasaki University Graduate School of Biomedical Sciences, Nagasaki, Japan. ${ }^{2}$ Clinical Research Center, Nagasaki University Hospital, Nagasaki, Japan. ${ }^{3}$ Division of Biostatistics, Kurume University School of Medicine, Fukuoka, Japan. ${ }^{4}$ Department of Respiratory Medicine, School of Medicine, University of Occupational and Environmental Health, Kitakyushu, Japan. ${ }^{5}$ Department of Cardiopulmonary Rehabilitation Sciences, Nagasaki University Graduate School of Biomedical Sciences, Nagasaki, Japan.

Received: 21 April 2016 Accepted: 6 July 2016

Published online: 11 July 2016

\section{References}

1. Travis WD, Costabel U, Hansell DM, King Jr TE, Lynch DA, Nicholson AG, Ryerson CJ, Ryu JH, Selman M, Wells AU, et al. An official American thoracic society/european respiratory society statement: update of the international multidisciplinary classification of the idiopathic interstitial pneumonias. Am J Respir Crit Care Med. 2013;188:733-48.

2. Raghu G, Collard HR, Egan JJ, Martinez FJ, Behr J, Brown KK, Colby TV, Cordier JF, Flaherty KR, Lasky JA, et al. An official ATS/ERS/JRS/ALAT statement: idiopathic pulmonary fibrosis: evidence-based guidelines for diagnosis and management. Am J Respir Crit Care Med. 2011;183:788-824.

3. Song JW, Hong SB, Lim CM, Koh Y, Kim DS. Acute exacerbation of idiopathic pulmonary fibrosis: incidence, risk factors and outcome. Eur Respir J. 2011;37:356-63.
4. Collard HR, Moore BB, Flaherty KR, Brown KK, Kaner RJ, King Jr TE, Lasky JA, Loyd JE, Noth I, Olman MA, et al. Acute exacerbations of idiopathic pulmonary fibrosis. Am J Respir Crit Care Med. 2007;176:636-43.

5. Kim DS, Collard HR, King Jr TE. Classification and natural history of the idiopathic interstitial pneumonias. Proc Am Thorac Soc. 2006;3:285-92.

6. Jeon K, Chung MP, Lee KS, Chung MJ, Han J, Koh WJ, Suh GY, Kim H, Kwon OJ. Prognostic factors and causes of death in Korean patients with idiopathic pulmonary fibrosis. Respir Med. 2006;100:451-7.

7. Kondoh Y, Taniguchi H, Katsuta T, Kataoka K, Kimura T, Nishiyama O, Sakamoto K, Johkoh T, Nishimura M, Ono K, Kitaichi M. Risk factors of acute exacerbation of idiopathic pulmonary fibrosis. Sarcoidosis Vasc Diffuse Lung Dis. 2010;27:103-10.

8. Natsuizaka M, Chiba H, Kuronuma K, Otsuka M, Kudo K, Mori M, Bando M, Sugiyama Y, Takahashi H. Epidemiologic survey of Japanese patients with idiopathic pulmonary fibrosis and investigation of ethnic differences. Am J Respir Crit Care Med. 2014;190:773-9.

9. Kim DS, Park JH, Park BK, Lee JS, Nicholson AG, Colby T. Acute exacerbation of idiopathic pulmonary fibrosis: frequency and clinical features. Eur Respir J. 2006;27:143-50

10. Judge EP, Fabre A, Adamali HI, Egan JJ. Acute exacerbations and pulmonary hypertension in advanced idiopathic pulmonary fibrosis. Eur Respir J. 2012;40:93-100

11. Kondoh $Y$, Taniguchi H, Ebina M, Azuma A, Ogura T, Taguchi Y, Suga M, Takahashi H, Nakata K, Sugiyama Y, et al. Risk factors for acute exacerbation of idiopathic pulmonary fibrosis - Extended analysis of pirfenidone trial in Japan. Respir Investig. 2015;53:271-8.

12. Ley B, Ryerson CJ, Vittinghoff E, Ryu JH, Tomassetti S, Lee JS, Poletti V, Buccioli M, Elicker BM, Jones KD, et al. A multidimensional index and staging system for idiopathic pulmonary fibrosis. Ann Intern Med. 2012;156:684-91.

13. Wells AU, Desai SR, Rubens MB, Goh NS, Cramer D, Nicholson AG, Colby TV, du Bois RM, Hansell DM. Idiopathic pulmonary fibrosis: a composite physiologic index derived from disease extent observed by computed tomography. Am J Respir Crit Care Med. 2003;167:962-9.

14. Sakamoto N, Mukae H, Fujii T, Kakugawa T, Kaida H, Kadota J, Kohno S. Soluble form of Fas and Fas ligand in serum and bronchoalveolar lavage fluid of individuals infected with human T-lymphotropic virus type 1. Respir Med. 2004;98:213-9.

15. Youden WJ. Index for rating diagnostic tests. Cancer. 1950:3:32-5.

16. Heagerty PJ, Lumley T, Pepe MS. Time-dependent ROC curves for censored survival data and a diagnostic marker. Biometrics. 2000;56:337-44.

17. Human Microbiome Project C. Structure, function and diversity of the healthy human microbiome. Nature. 2012;486:207-14.

18. Han MK, Zhou Y, Murray S, Tayob N, Noth I, Lama VN, Moore BB, White ES, Flaherty KR, Huffnagle GB, et al. Lung microbiome and disease progression in idiopathic pulmonary fibrosis: an analysis of the COMET study. Lancet Respir Med. 2014;2:548-56.

19. Molyneaux PL, Cox MJ, Willis-Owen SA, Mallia P, Russell KE, Russell AM, Murphy E, Johnston SL, Schwartz DA, Wells AU, et al. The role of bacteria in the pathogenesis and progression of idiopathic pulmonary fibrosis. Am J Respir Crit Care Med. 2014;190(8):906-13.

20. Idiopathic Pulmonary Fibrosis Clinical Research N, Raghu G, Anstrom KJ, King Jr TE, Lasky JA, Martinez FJ. Prednisone, azathioprine, and $\mathrm{N}$-acetylcysteine for pulmonary fibrosis. N Engl J Med. 2012;366:1968-77.

21. Papiris SA, Kagouridis K, Kolilekas L, Papaioannou Al, Roussou A, Triantafillidou C, Baou K, Malagari K, Argentos S, Kotanidou A, et al. Survival in Idiopathic pulmonary fibrosis acute exacerbations: the non-steroid approach. BMC Pulm Med. 2015;15:162.

22. Pesci A, Ricchiuti E, Ruggiero R, De Micheli A. Bronchoalveolar lavage in idiopathic pulmonary fibrosis: what does it tell us? Respir Med. 2010;104 Suppl 1:S70-73.

23. Tabuena RP, Nagai S, Tsutsumi T, Handa T, Minoru T, Mikuniya T, Shigematsu M, Hamada K, Izumi T, Mishima M. Cell profiles of bronchoalveolar lavage fluid as prognosticators of idiopathic pulmonary fibrosis/usual interstitial pneumonia among Japanese patients. Respiration. 2005;72:490-8.

24. Kinder BW, Brown KK, Schwarz MI, Ix JH, Kervitsky A, King Jr TE. Baseline BAL neutrophilia predicts early mortality in idiopathic pulmonary fibrosis. Chest. 2008;133:226-32.

25. Kishaba T, Shimaoka Y, Fukuyama H, Nagano H, Nei Y, Yamashiro S, Tamaki $\mathrm{H}$. Clinical characteristics of idiopathic pulmonary fibrosis patients with gender, age, and physiology staging at Okinawa Chubu Hospital. J Thorac Dis. 2015;7:843-9. 
26. Hyldgaard C. A cohort study of Danish patients with interstitial lung diseases: burden, severity, treatment and survival. Dan Med J. 2015;62:B5069.

27. Ley B, Collard HR, King Jr TE. Clinical course and prediction of survival in idiopathic pulmonary fibrosis. Am J Respir Crit Care Med. 2011;183:431-40.

28. Greene KE, King Jr TE, Kuroki Y, Bucher-Bartelson B, Hunninghake GW, Newman LS, Nagae H, Mason RJ. Serum surfactant proteins-A and -D as biomarkers in idiopathic pulmonary fibrosis. Eur Respir J. 2002;19:439-46.

29. Takahashi H, Fujishima T, Koba H, Murakami S, Kurokawa K, Shibuya Y, Shiratori M, Kuroki Y, Abe S. Serum surfactant proteins A and D as prognostic factors in idiopathic pulmonary fibrosis and their relationship to disease extent. Am J Respir Crit Care Med. 2000;162:1109-14.

30. Barlo NP, van Moorsel CH, Ruven HJ, Zanen P, van den Bosch JM, Grutters JC. Surfactant protein-D predicts survival in patients with idiopathic pulmonary fibrosis. Sarcoidosis Vasc Diffuse Lung Dis. 2009;26:155-61.

31. Selman M, King TE, Pardo A, American Thoracic S, European Respiratory S, American College of Chest P. Idiopathic pulmonary fibrosis: prevailing and evolving hypotheses about its pathogenesis and implications for therapy. Ann Intern Med. 2001;134:136-51.

32. Chung MP, Monick MM, Hamzeh NY, Butler NS, Powers LS, Hunninghake GW. Role of repeated lung injury and genetic background in bleomycininduced fibrosis. Am J Respir Cell Mol Biol. 2003;29:375-80.

33. Azuma A, Nukiwa T, Tsuboi E, Suga M, Abe S, Nakata K, Taguchi Y, Nagai S, Itoh $\mathrm{H}$, Ohi M, et al. Double-blind, placebo-controlled trial of pirfenidone in patients with idiopathic pulmonary fibrosis. Am J Respir Crit Care Med. 2005;171:1040-7.

34. Taniguchi $H$, Ebina M, Kondoh Y, Ogura T, Azuma A, Suga M, Taguchi Y Takahashi H, Nakata K, Sato A, et al. Pirfenidone in idiopathic pulmonary fibrosis. Eur Respir J. 2010;35:821-9.

35. Collard HR, Yow E, Richeldi L, Anstrom KJ, Glazer C, investigators IP. Suspected acute exacerbation of idiopathic pulmonary fibrosis as an outcome measure in clinical trials. Respir Res. 2013;14:73.

36. Ryerson CJ, Cottin V, Brown KK, Collard HR. Acute exacerbation of idiopathic pulmonary fibrosis: shifting the paradigm. Eur Respir J. 2015;46:512-20.

37. Richeldi L, du Bois RM, Raghu G, Azuma A, Brown KK, Costabel U, Cottin V, Flaherty KR, Hansell DM, Inoue Y, et al. Efficacy and safety of nintedanib in idiopathic pulmonary fibrosis. N Engl J Med. 2014;370:2071-82.

\section{Submit your next manuscript to BioMed Central and we will help you at every step:}

- We accept pre-submission inquiries

- Our selector tool helps you to find the most relevant journal

- We provide round the clock customer support

- Convenient online submission

- Thorough peer review

- Inclusion in PubMed and all major indexing services

- Maximum visibility for your research

Submit your manuscript at www.biomedcentral.com/submit

CBiomed Central 